\title{
Application of neural network technologies for management development of systems
}

A.L. Lisovsky ${ }^{1}$

1 "Krypten" JSC

\section{ABSTRACT}

Work is devoted to application of neural network technologies for management development of systems. In article the analysis of efficiency of introduction of neural network technologies is carried out to business processes of three Russian companies and the positive effect locates when using neural networks in several parameters.

The case analysis is added with the analysis of economic feasibility of introduction of neural networks by means of an assessment of studied indicators, an assessment of satisfaction of clients, control of the personnel, an assessment of efficiency of each employee. Recommendations about application of neural networks in the organization are made.

In article it is shown that in spite of the fact that many actions necessary for introduction of system, are costly and long-term, they will positively affect company activity.

\section{KEYWORDS:}

artificial intelligence, neural networks, information technologies, improvement of business processes.

\section{FOR CITATION:}

Lisovsky A.L. (2020). Application of neural network technologies for management development of systems. Strategic Decisions and Risk Management, 11(4), 378-389. DOI: 10.17747/2618-947X-2020-4-378-389. 


\section{INTRODUCTION}

One of the promising areas of maintaining and improving the competitiveness of organizations is the use of neural network technologies, since they contribute to meeting the needs of customers at minimal cost.

The rapid development of information technologies in recent decades, their implementation in all spheres of life has led to the fact that today it is impossible to imagine even a small business that would not be equipped with IT infrastructure. At the same time, there is a growing need to develop new intelligent systems to support management decisions and adapt them to the widest possible range of conditions. The most promising direction here is the use of artificial neural networks.

The relevance of the research topic is determined by the need to improve the use of neural network technologies in the management of an organization by adapting them to the conditions of a changing competitive environment, as well as the growth and qualitative complexity of consumer requests.

The purpose of this article is to analyze the implementation of neural network technologies in the business processes of the organization and evaluate their effectiveness.

\section{FEATURES OF INTERPRETATION OF THE CONCEPTS OF ARTIFICIAL INTELLIGENCE AND NEURAL NETWORKS}

Over the past few decades, many intelligent computer systems have been created that can perform various tasks to simplify human life. In particular, there are computer systems that can diagnose diseases, plan treatment, perform operations, create complex organic chemical compounds, solve complex mathematical equations in symbolic form, analyze electronic circuits, understand and parse a limited amount of human speech and natural language text, or write small computer programs to meet the formal needs of a person and an organization [Morhat, 2018].

Based on the terminology, artificial intelligence (AI) is a program that can, while learning, effectively perform a certain task. If it is a specialized program designed to solve a narrow problem (for example, a game of chess), the $\mathrm{AI}$ is called weak for its ability to understand and create activities only in this area [Naumova, Sharafutdinov, 2015]. For example, Alpha Zero, a program based on neural networks and trained to play chess, is now a contender for the title of the most powerful chess player in the world.

The term "strong artificial intelligence" (or "general artificial intelligence") is reserved for hypothetical programs that are able to independently learn different tasks (that is, do not have special programming for specific tasks). The creation of such a program is not expected in the next five years [Beitz, 2018]. 
The wording of the term AI does not mention a neural network, since this term describes more a specific technology, rather than a tool. The term "neural networks" describes the end result - the ability to learn and use the learned content. That is, AI can be created on the basis of neural networks, but perhaps without them.

On the other hand, the term "neural network" describes only the methods (ideas, methods) of programming. The idea is to create a basic structure with the most general purpose that it will need to use, instead of programming all actions with commands, such as classical programming. At the same time, this structure is based on a huge number of parameters, but they remain purposefully empty. In many ways, this structure is similar to the activity of the human brain (hence the term "neural network"). After a huge number of steps (from hundreds of thousands to millions), so to speak, the real task determines which specific values will give the best result [Bowman et al., 2018].

Artificial neural networks (hereinafter - ANN) calculate structures that can consist of a large number of elements, and each of these elements performs relatively simple functions [Rosellini, D'Haese, 2017]. From the very beginning, the neural network device was considered mainly to solve the problem of classification, grouping and recognition of models, but further development of this direction significantly expanded the scope of the neural network method, and new methods began to be developed.

\subsection{STAGES OF DEVELOPMENT OF ARTIFICIAL NEURAL NETWORKS}

The first attempt to uncover the secrets of high brain efficiency was made by S. Ramon y Cajal [Ramon y Cajal, 1911], in his work he expressed the idea of neurons as structural units of the brain. Nevertheless, neurons have a response rate that is 5-6 orders of magnitude lower than a semiconductor logic gate. As recent research has shown, the secret to brain performance lies in the large number of neurons and the huge connections between them.

The neural network that forms the human brain is an efficient, complex, nonlinear, almost parallel information processing system [Rumelhart et al., 1986]. It is able to organize its neurons to achieve image perception, recognition, or motion control faster than the most modern and powerful computers faced with the same tasks [Broomhead, Lowe, 1988].

An artificial neural network is a simplified model of the brain. It is based on artificial neurons, which have the same basic properties as living ones: plasticity and flexibility. The use of brain structures and the plasticity of neurons make the artificial neural network a global information processing system. Thus, we can say that an artificial neural network is a machine that simulates the work of the brain.

Usually, an artificial neural network is represented in the form of electronic devices, computer programs, and software. Among the many possible definitions, we can mention the definition of an ANN as an adaptive machine, which is given in [Aleksander, Morton, 1990]: an ANN is "a parallel distributed processor that has a natural tendency to preserve experienced knowledge and the ability to provide it". Its similarity to the brain can be noted in two aspects: (1) knowledge is acquired by the network in the process of learning; (2) the forces and properties of interneuronal connections, also called synaptic weights, are used to preserve the acquired knowledge.

The procedure that is used to create the ability to carry out the learning process is referred to in ANN theory as the learning algorithm. Its function is to change the synaptic weights of the neural network in a certain way to acquire the necessary properties.

The start of the development of the modern ANN began in 1943 with the pioneering work of W. McCulloch and W. Pitts [McCulloch, Pitts, 1943]. In this paper, McCulloch and Pitts introduced the concept of "threshold logic neurons" and described the logical model of instructions.

In 1948, N. Wiener's famous book related to neural networks, "Cybernetics", was published, which describes many important control concepts. Later editions of the book added chapters on learning, self-organization, and neuropsychology [Wiener, 1968].

The next event that contributed to the development of ANN was the publication of D. Hebb's book [Hebb, 1949]. Hebb suggested that connections in the brain develop as the body learns new functional tasks and creates neural assemblies, resulting in neural ensembles. Hebb follows the previous Ramon-y-Cajal hypothesis and introduces the "learning hypothesis", which states that the efficiency or gain of a variable synapse between two neurons is increased by the synapse during the reactivation of the other neuron.

Hebb's book was a real breakthrough in the system of training and adaptation. The paper [Rochester et al., 1956] probably made the first attempts to use computer modeling for theoretical test companies. In the same year, A. Uttley [Uttley, 1956] proved that modules with modifiable synapses can be trained to classify simple sets of binary models into appropriate classes. In his subsequent work, Uttley also suggested that the performance of variable synapses in the nervous system may depend on the statistical relationship between changing states on both sides of the synapse, which leads to a connection with Shannon's information theory [Uttley, 1979].

In 1952, the book was published by W. Ashby [Ashby, 1952]. Its essence boils down to the fact that the adaptive behavior of existing living systems is not formed only by heredity, but can appear and change in the process of learning, and that usually in the process of learning, the behavior of living systems can improve.

One of the key moments in the history of ANN development is M. Minsky's doctoral dissertation of 1954 [Minsky, 1954]. In 1961, he published an article [Minsky, 1961], which describes artificial intelligence, and also contains a section on what is now called an artificial neural network.

About 15 years after the article by McCulloch and Pitts, F. Rosenblatt, in his work on perception [Rosenblatt, 1958], proposed an innovative approach to solving the problem 
of pattern recognition. In it, the so-called perceptron convergence theorem was derived, the proof of which was formulated only in 1960 .

In 1962, B. Widrow and his students presented one of the first trained ANN with a multi - layered structure - Madaline [Widrow, 1962].

The idea of an overabundance of J. von Neumann prompted S. Vinogradov and J. Cowan to create a check for the representation of the distributed redundancy of the ANN [Winograd, Cowan, 1963]. A major development was also Cowan's introduction of the sigmoid activation function for the logical neuron model in 1967 [Cowan, 1967].

In 1969, the book [Minsky, Papert, 1971] was published, where the existence of the main limitations of the skills of monolayer perception was mathematically proved. The authors also showed that a single-layer network of any size cannot solve the problems that exist in a multi-layer configuration.

For the multi-level perceptron, the 1970s brought nothing new. This is partly due to the low level of funding, and partly due to the lack of personal computers. However, during the same period, significant results were achieved in the development of self-organizing maps based on competitive training: in 1976, D. Wilshaw and K. von der Malsburg published their first work [Willshaw, Malsburg, 1976] on self-organizing maps.

Since the early 1980 s, a new period in the formation and development of artificial neural networks has begun. An important event of that time was the development of an ANN with a fully connected structure and an original algorithm for creating weights. In 1982, as a follow-up to Malsburg's research, the work of T. Kohonen [Kohonen, 1982]. Nevertheless, real progress in the use of ANN to solve practical problems, including control, became noticeable only after D. Rumelhart, J. Hinton and R. Williams described the back propagation algorithm in 1986 [Rumelhart, 1986]. This was the first effective algorithm for forming a multilayer perception of any structure.

In 1988, the last major discovery in ANN theory was made - the introduction of RBF networks by D. Broomhead and D. Lowe [Broomhead, 1988]. It is an alternative to the multilayer perceptron system for a hierarchical linear network that uses hidden neurons with radial activation functions. Ideologically, the idea of radial basic functions is related to the method of potential functions, proposed in 1964 by O. Bashkirov, E. Brauerman and I. Muchnik [Bashkirov et al., 1964]. In [Broomhead, 1988], new methods of ANN synthesis were proposed, much attention was paid to the connection between ANN and classical methods of numerical analysis and the definition of the theory of linear adaptive filters.

\subsection{TRENDS IN THE USE \\ OF ARTIFICIAL NEURAL NETWORKS}

An ANN can be used to reproduce many relationships between many objects. The main difference between artificial neural networks and traditional software systems is that the former do not require programming, they can be configured independently, that is, they understand the needs of the user [Zvenger, Nizamov, 2017]. Most often, the tasks that an information system solves can be reduced to many typical tasks, including neural network technology, and can solve the following problems [Trachuk et al., 2018]:

1) recognition of human speech and abstract images;

2) classification of recognized images, that is, the distribution of the image into groups;

3) clustering - the division of images into previously undefined groups based on some characteristics;

4) classification of the state of complex systems;

5) function approximation - estimation of unknown dependence, following experimental data;

6) forecast as a definition of the future process based on the past and present;

7) optimization - finding solutions that maximize or minimize a certain quality criterion under given constraints;

8) content-addressable memory, i.e. associative memory - accessible by the specified content;

9) management as a translation and maintenance of the system in the required state.

Of all these problems, the management problem is the most difficult, and in most cases, its solution should also solve the other listed problems.

The following applications of neural networks are known:

- economics and business - managing technological processes and financial indicators, predicting the behavior of market players and market dynamics in general, predicting the bankruptcy of an organization, assessing the value of real estate, automatic data rating, assessing the creditworthiness of a company and individuals, forecasting exchange rates, solving analytical, research, and predictive tasks that are associated with extensive information data;

- medicine-diagnostics of diseases and other problems, processing of medical images, selection of a combination of various medicines, etc.;

- internet technologies - search for the necessary information;

- production automation - optimization of the production process, introduction of automation modes, product quality diagnostics, warning and automatic avoidance of an emergency;

- political technologies - generalization and analysis of opinion polls, counting of political votes in the event of elections, etc.;

- security at different levels - personal identification systems, recognition of car license plates and images from space orbits;

- geological exploration - analysis of seismic indicators, assessment of resources of mineral deposits. 
As a powerful technical tool, neural network technology helps to make important and non-obvious decisions in uncertain conditions, lack of time and limited information resources.

Neural networks will also be preferred if there are many hidden input patterns in a particular pattern. In this case, you can almost automatically take into account the various nonlinear interactions between the indicators of the characteristics of this data. This is especially important in information processing systems (distributed databases, telecommunications, and expert systems) for the preliminary stage of analysis or selection, as well as the detection of "drop-out facts" or serious errors in human decision-making.

It is recommended to use the neural network method when loading incomplete or" noisy " information, as well as in a problem where the solution can be found visually. The advantages of neural networks become obvious when the "rules of the game" often change. That is why a neural network is used to determine the state of the stock market, which is characterized by a set of constantly changing indicators.

A distinctive feature of neural networks, as already noted, is their ability to change their behavior, depending on changes in the environment, extracting hidden patterns from the data stream - learning [Akhmetzyanov et al., 2020]. At the same time, the learning algorithm does not require prior knowledge of the existing relations in the subject area - it simply selects a sufficient number of examples to describe the behavior of the modeling system in the past.

Technologies based on neural networks do not impose higher requirements on the accuracy of input data both during training and during use (after all settings and training), for example, when identifying symptoms close to a critical situation, so the neural network technology has two useful properties:

1) the ability to learn from a specific set of examples;

2) the ability to consistently identify, predict new situations with high accuracy, and in front of external interference, such as conflict or incomplete values, arising in the flow of information.

Based on brain activity, neural network technology includes many biological terms, concepts, and parameters. From the point of view of modeling complex systems, a large number of different types of neural networks with their own distinctive characteristics have been developed [Kournikov et al., 2017]. The most common multi-level neural networks, or multi-level perception, are Multi-Layer Perceptron (MLP).

The network consists of artificial neurons, the main converters, interconnected by information connections, determined by the structure. One of the main differences between neural networks is the ability to do parallel computations, which increases the efficiency of the computational process [Kornina et al., 2018]. It is based on the concept of artificial neurons, which allows the nonlinear function of several variables to be implemented in practice.

\subsection{AREAS OF APPLICATION OF NEURAL NETWORK TECHNOLOGIES IN MODERN CONTROL SYSTEMS}

Neural networks are computational tools for developing models that help identify various patterns and relationships in the analyzed data. The data used to develop these models is called training data [Kovalev, 2020]. Neural networks can be used for:

- predicting future events based on observed historical training data;

- classifying invisible data into predefined groups based on the characteristics observed in the training data;

- grouping training data into natural groups based on the similarity of characteristics in the training data.

Neural networks are now recognized worldwide as the most effective and appropriate artificial intelligence technology for pattern recognition. Excellent results in the field of pattern recognition can be directly applied for commercial purposes in the field of forecasting, classification and data analysis. This new approach provides an additional advantage in solving real-world problems in business and engineering [Zuev, Kemaykin, 2019]. However, to produce optimal results, neural networks require proper data preprocessing, architecture selection, and network training. In the past, most failures in the use of neural networks were due to the fact that users did not have sufficient skills in the appropriate data preparation and design of neural networks. It is these two issues that have prevented many businesses from exploiting the huge potential of this promising technology. Thanks to automatic data preprocessing techniques and architecture selection algorithms, neural networks have become quite easy to use without any expensive training.

The existing control systems can be classified as follows [Kovalev, 2020]:

1) a classical control system based on the theory of automatic control with different mathematical methods of data processing;

2) a management system that is built on the basis of fuzzy logic and an expert system;

3) a control system based on genetic algorithms and artificial neural networks.

The advantages of the neural network management method are:

1) no restriction on the linearity of the system;

2) after completing the training, the control is carried out in real time;

3) performance in noise conditions;

4) neural network control systems are considered more adaptive to real-world conditions.

However, when using neural networks, there are difficulties associated with unreliability, since artificial neural networks can be inaccurate even under normal conditions. Therefore, for critical tasks, the use of neural networks must be replicated by other systems, and the future 
of intelligent control lies in combining traditional control with an artificial system based on neural networks.

The research interest of this article lies in the question of how effective the use of neural network technologies for management is.

\section{RESEARCH METHODOLOGY}

The formulated research question provides that an inductive approach should be applied in the course of an empirical study. Accordingly, it is necessary to use a research method that, when collecting the necessary data, will be sufficiently flexible, which will allow "to study information that is independent of existing theories" [Yunusova, Magsumova, 2019]. The most suitable method for these conditions is the case analysis method. Among other things, case analysis is considered applicable for collecting confidential information and for further comparing the level of perception of top management with the process of making managerial decisions, which is suitable for our case, since the entire analysis was based on internal confidential data obtained during pilot project launches and not published in the media and other information sources.

Thus, the empirical analysis was carried out on the basis of information from the Russian company "Heedbook Cloud", which uses neural network technologies in its activities to assess the effectiveness of companies in the service sector.

The case analysis includes an analysis of three pilot projects conducted from 2017 to 2019 in three companies operating in different areas of customer service. Customer service in this case involves interaction with customers as a result of sales, consulting, additional service.

The first case considered is a pilot project in the MFC of Reutov. A multifunctional center is a state institution in Russia that provides state and municipal services in a single window mode after an interested person makes a request ${ }^{1}$.

The second is a pilot project in the telecommunications company YOTA, a federal operator of wireless cellular communications with coverage in $2 \mathrm{G} / 3 \mathrm{G} / 4 \mathrm{G}$ networks ${ }^{2}$. The main activities of the company are the provision of mobile communication services and 4G Internet.

The third case analysis was carried out by TUI, one of the leading travel companies in Russia, which includes a tour operator and a network of travel agencies. ${ }^{3}$ oThe company is part of the international tourism holding company TUI Group with more than 40 years of experience. In Russia, TUI was established in 2009 on the basis of Russian tour operators VKO Group and Mostravel.

Despite the fact that the selected companies work in different industries: the provision of public services, mobile and Internet services, travel services, that is, they produce different products and are aimed at different consumers, their audiences may overlap. Data collection. The main materials for the case analysis were collected for three projects that formed the basis of the study. Also, thanks to communication with the employees of the company implementing artificial intelligence in these projects, a structured analysis of the data obtained during the pilot projects was carried out, which allowed us to interpret the results.

Data analysis. The traditional "grounded theory" approach was applied, which makes it possible to consistently compare the analyzed data with the emerging theoretical construction [Linder, Arsenova, 2016].

The data analysis procedure was carried out in three stages: the first stage highlighted the key points of the company's development.

At the second stage, pilot projects were considered that had common characteristics regarding the results obtained from the use of new technologies and the future prospects for their application.

At the third stage, the main points of evaluating the performance of the service and the need to improve its business processes related to customer satisfaction were identified. Then conclusions were drawn about the role of the introduction of neural network technologies in business processes.

\section{ANALYSIS OF THE IMPLEMENTATION OF NS TECHNOLOGIES IN COMPANIES}

All the considered cases represent the results of pilot projects implemented by the company "Heedbook Cloud", specializing in strategic computer technologies in the field of video and audio data analysis using machine learning tools. Heedbook Cloud LLC is the only Russian company that is part of Microsoft's Global AI Inner Circle program.

The main activity of the company is the introduction of online services for assessing and monitoring compliance with quality standards of service and sales by employees of the front line of service companies with the possibility of placing the service on the customer's servers (onpremis).

The operation of the Heedbook service consists in the fact that the system processes the video and audio stream from the webcam of an employee of the front line of a retail point of sale in the background. Based on information about the behavior of the client and employee, the program:

- objectively assesses customer satisfaction, works in the background, without distracting employees and without boring customers with surveys;

- provides accurate information about the number and duration of conversations, the level of customer workload at the point of sale;

- ranks employees by service quality, efficiency, and sales quality, automatically identifying lagging employees and leaders;

- evaluates peak loads and downtime, helps to correctly distribute shifts and staffing; 
Figure 1.

Logic of implementation and operation of the program based on NS-technologies

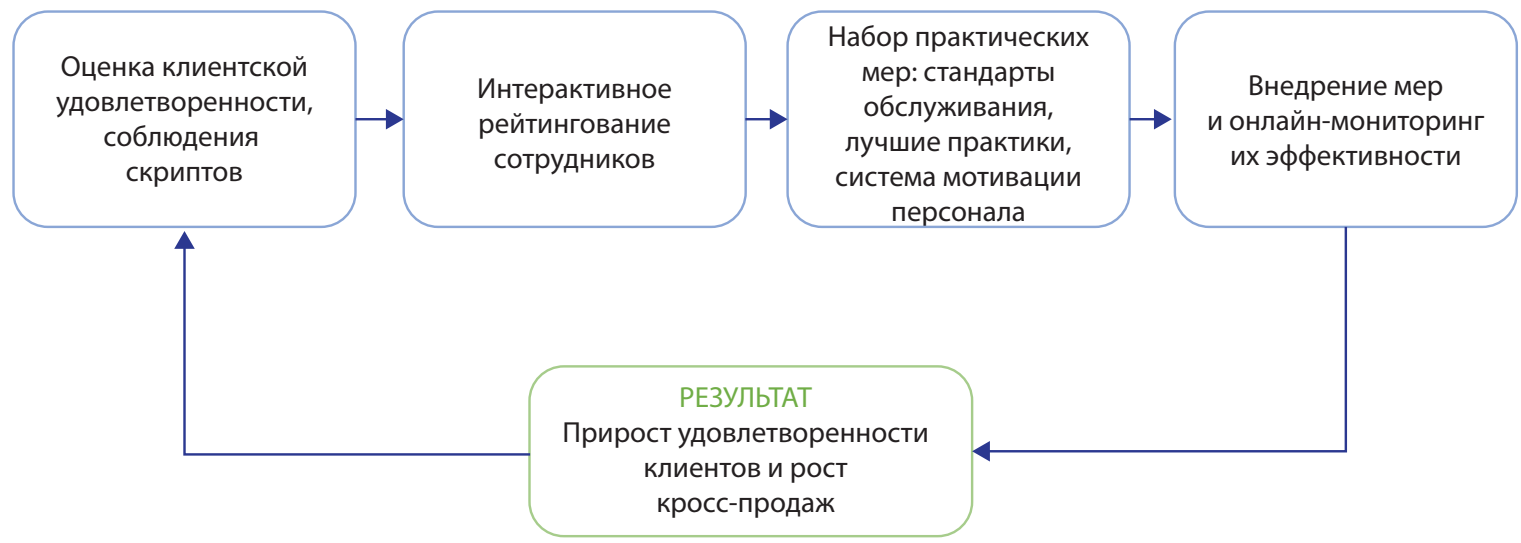

- checks the availability of additional product offerings, ensures compliance with scripts and service standards.;

- analyzes the customer's reactions to special offers, helping the company to understand what causes negative or positive emotions in the customer, etc.

The principle of operation of the program is based on the sequential implementation of the steps shown in Figure 1.

As shown in the figure, the work of the program based on NS technologies includes five stages:

1. The assessment of customer satisfaction with the service and compliance with the scripts by employees is performed automatically by the Heedbook system in online mode.

2. Employees are rated interactively based on their performance.

3. As a result, the company can monitor the results and take measures to improve the work, such as the introduction of new service standards, the analysis of best service practices and training of employees on this material, the development of new employee motivation systems.

4. The implementation of measures is carried out in conjunction with the Heedbook system - it provides feedback.

5. The result is measured in an increase in customer satisfaction and profit growth, while the system is continuously provided with new data for further improvements on the part of the business.

At the moment, the company "Heedbook Cloud" is conducting pilot studies of the implementation of AI based on the presented algorithm of the program in YOTA, Megafon, Sovcombank, AK Bars Bank, Russian Post. In 2021, the company plans to enter the markets of the United States, Germany, France, and Italy (with the support of KPMG). By the end of 2021, Heedbook Cloud plans to receive at least $50 \%$ of its revenue from international customers.

Next, we will analyze the cases of the company "Heedbook Cloud" using neural network technologies in control systems.
As already mentioned, three cases of companies that have implemented NS technologies were selected for the analysis: the MFC, YOTA and TUI projects. The analysis and description of these cases are given in Table 1.

As a result of the analysis of the pilot projects of the company "Heedbook Cloud", the following competitive advantages of neural network technologies in business management were identified, including the advantages of the Heedbook service.

1. Instant automatic data processing without human intervention.

2. A well-founded system of online recommendations for employees of the enterprise as an auxiliary tool for improving the quality of service: an employee can adjust his behavior depending on the type of customer, even without having experience in sales - actions cease to be intuitive.

3. The use of reliably measurable psychophysiological parameters (poorly controlled physiological manifestations of a person's temperament, innately conditioned and almost unchanged during life) to profile the client instead of situational interpretations of behavior.

4. Automatic recommendations to the employee-an innovative system of instant feedback on client work is based on artificial intelligence and competencies, in particular, the "Heedbook" team (and a group of attracted experts), in the field of sales and psychology, allows you to adjust the work of employees based on the current situation with the possibility of subsequent analysis of the case.

At the same time, despite the success of the pilot projects and the demand for the solution in the market, replication of the service is difficult, since almost all large customers are not ready to use products on cloud technologies for security and data protection reasons. 
Table 1

Analysis of cases of implementation of NS-technologies

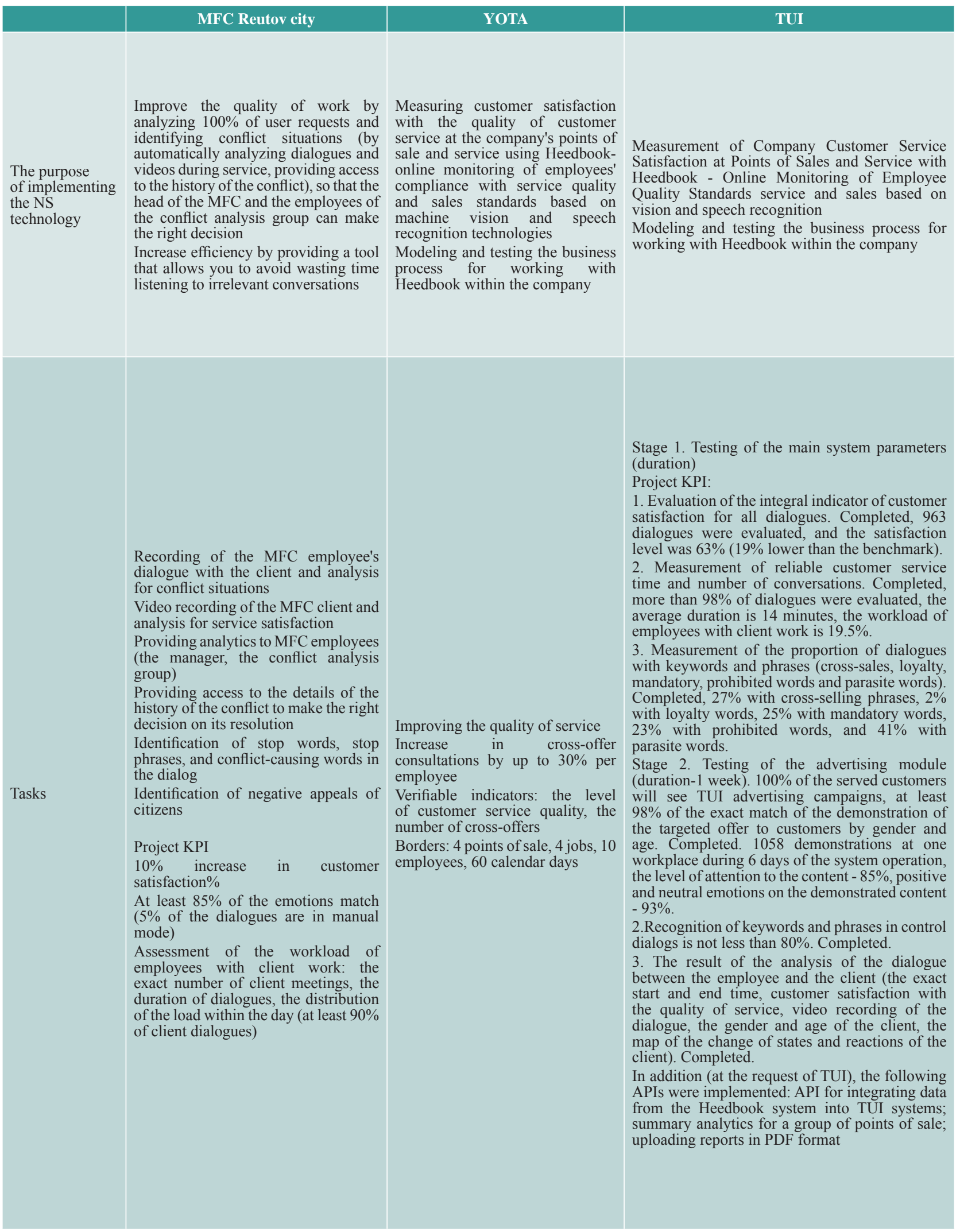


Table 1

Analysis of cases of implementation of NS-technologies

\begin{tabular}{l|l}
\hline \multicolumn{1}{|c}{ MFC Reutov city } \\
\hline & $\begin{array}{l}\text { Men conversations with clients } \\
\text { Does not interfere with the execution } \\
\text { of the direct functionality of the } \\
\text { employee, works in the background } \\
\text { Does not require additional software } \\
\text { and hardware } \\
\text { The quality of speech recognition } \\
\text { is hindered by the glass partition } \\
\text { between the client and the employee } \\
\text { During the pilot, significant } \\
\text { improvements to the service were } \\
\text { implemented } \\
\text { Technical the future, it is necessary to refine } \\
\text { results } \\
\text { the speaker separation system and } \\
\text { connect a second camera to shoot the } \\
\text { employee }\end{array}$
\end{tabular}

The majority (96\%) of dialogues leave a slight emotional trace

Among the employees of the MFC, the leaders in terms of customer loyalty were identified

AI The presence and notification of clients implementation about the recording and analysis of results dialogues significantly reduced the number of conflict situations

The function of live broadcast from workplaces and PUSH notifications about events on the front line allowed to improve labor discipline

1. Continue operating the system in the MFC of Reutov city

2. Go to the system's OPE in $20 \mathrm{MFC}$ 's of the Moscow region by the end of the year, followed by a circulation to all MFC's of the region

3. Together with the company "Heedbook Cloud" to create a KPI for the quality of customer service in the MFC of the Moscow region and a roadmap for its improvement

\section{YOTA}

1408 customer conversations, customer coverage $-57 \%$

For each of them, the following parameters are formed:

- video recording of the dialog (with the exact start and end time);

recognition of keywords and phrases in the dialog (YOTA scripts and the Heedbook script library);

- map of changing client states and reactions;

- gender and age of the client;

- the level of customer satisfaction, the change in the mood of the client in the process of communication

The customer service quality index increased from $53 \%$ (first week) to $61 \%$ (last week) due to: - improve service control;

- keyword database updates for service quality control

Number of cross-offers: there is potential for growth due to recommendations to staff and constant monitoring

CPI: Increase Cross-Offer Consultation to $30 \%$ for Each Employee

Create and provide personal recommendations to front-line employees with the help of the management manager and the YOTA group of business coaches
TUI

963 conversations with clients

For each of them, the following parameters are formed:

- video recording of the dialog (with the exact start and end time);

- recognition of keywords and phrases in the dialog (TUI scripts and the Heedbook script library);

- map of changing client states and reactions, - gender and age of the client;

- the client's reaction to the advertising content shown in the course of communication;

- the level of customer satisfaction, the change in the mood of the client in the process of communication

All customer conversations were automatically evaluated on the topic of customer satisfaction based on the analysis of more than 20 parameters of customer and employee behavior extracted using machine learning tools from video and audio catalogs.

The manager has access to the analysis of each dialogue between the manager and the client: the rating of employees on the quality of service, understanding the reasons for satisfaction, changes in customer satisfaction by day of the week, hours

The customer service quality index increased from $46 \%$ to $64 \%$ due to:

- improve service control;

- updates the phrases base for quality control of service;

- active work and a large number of customers served;

- overall reduction of the load on employees.

The quality indicator is in the green zone, but below the benchmark (the average indicator of companies using service scripts, the current leader is the bank's personal managers, the customer satisfaction indicator is $82 \%$ )

Additionally, use the Heedbook service to send PUSH notifications to employees (selfassessment based on the results of a client visit) and their managers (notification of negative feedback from the client). This functionality can also be used in TUI offices for centralized survey completion by employees

\section{CONCLUSIONS} AND PRACTICAL

\section{RECOMMENDATIONS}

The analysis made it possible to identify several ways to improve the efficiency of business processes when implementing neural network technologies - they are presented in Table 2.

When implementing NS technologies in the business processes of an organization, you can achieve the following optimization:
- some systems work in offline mode, which allows you to focus on those issues where the NS has not yet been implemented;

- save time in analytical processes;

- providing prompt feedback;

- monitoring employees' compliance with the principles and internal rules of the organization;

- automatic appearance of new input data for analytics, as the system is self-learning.

In the considered cases, the introduction of neural networks allowed us to achieve the following results:

- automatic tracking of customer service quality; 
- elimination of the human factor and errors in the assessment of personnel performance;

- fast online profiling of $100 \%$ of clients without their involvement and without the involvement of expensive experts;

- online recommendations to employees for situational correction of their behavior;

- increasing the number of cross-sales;

- daily training of employees in personal work with clients;

- increase of qualitative and quantitative indicators in the work of companies.

Based on this, organizations can offer the following recommendations for implementing the NS in their business processes.

1. Neural networks can replace the traditional approach to organizational rapid diagnostics of clients (surveys, tests, expert evaluation, etc.), which is a long, expensive, difficult to validate and sometimes unrealizable process in an office environment.

2. Automatic recommendations and profiling of the service will be an important addition to the existing customer loyalty management system, increasing the efficiency of business processes and the growth of cross-sales of companies.

3. The development of digital technologies and the transfer of routine operations to remote channels forces companies to actively transform their business processes. To do this, it is necessary to implement smart analytical tools and services based on artificial intelligence.

Table 2

Performance indicators of business processes in the implementation of neural network technologies

\begin{tabular}{|c|c|c|}
\hline $\begin{array}{l}\text { System performance } \\
\text { indicators }\end{array}$ & $\%$ & Reason \\
\hline $\begin{array}{l}\text { Growth of the integral } \\
\text { indicator of customer } \\
\text { satisfaction }\end{array}$ & $10^{\mathrm{a}}$ & $\begin{array}{l}\text { Improving the competence } \\
\text { of employees in the field } \\
\text { of communication with } \\
\text { the client }\end{array}$ \\
\hline Sales growth & $14^{\mathrm{b}}$ & $\begin{array}{l}\text { Personalize your offers based } \\
\text { on your customer profile }\end{array}$ \\
\hline Cross-sales growth & $19^{c}$ & $\begin{array}{l}\text { Personalization of sales scripts, } \\
\text { analysis of customer reactions }\end{array}$ \\
\hline Cost savings & $5^{d}$ & $\begin{array}{l}\text { Adjusting workload and } \\
\text { headcount }\end{array}$ \\
\hline $\begin{array}{l}\text { Creating a database } \\
\text { of customer profiles }\end{array}$ & 100 & $\begin{array}{l}\text { Online profiling of } 100 \% \\
\text { of client meetings }\end{array}$ \\
\hline $\begin{array}{l}\text { Based on a pilot project in the } \\
\text { Based on the results of the in } \\
\text { The analysis of the result of i } \\
\text { using the Heedbook service we } \\
\text { average and average employee }\end{array}$ & $\begin{array}{l}\text { of } R \\
\text { on }\end{array}$ & $\begin{array}{l}\text { city. } \\
\text { ameleon Group technology in Sberbank. } \\
\text { sonal recommendations to employees when } \\
\text { pulling lagging employees to the level of } \\
\text { the best). } \\
\text { ance (TimeBook). }\end{array}$ \\
\hline
\end{tabular}

4. As a result of this implementation, the company can track the results and take measures to improve offline performance.

5. Any technological change in the company must be economically justified. In the case of NS technologies, you need to understand which processes need to be optimized in order to achieve automation of routine and long-term ones.

\section{CONCLUSION}

The scope of application of neural networks is very diverse. At the same time, each of the created neural networks is related and trained only for the set goals and objectives and never goes beyond the designated boundaries, developing only in this direction.

Neural networks are an invaluable source of information about the customer for various companies, which in the future may replace the usual tools for segmentation and targeting, since a neural network that knows all the needs of a potential buyer can tell what he wants.

The undeniable advantage of the network model is its ability to change with the appearance of new observations and/or use the created model to solve similar problems, taking into account new input variables.

Neural network-based forecasting has a number of drawbacks. Usually, a large number of observations are required to create an acceptable model, in addition, for the purposes of training the network, it is necessary to carefully select the weight ratio of factors. Despite these disadvantages, the use of neural networks provides significant advantages in forecasting compared to simpler statistical methods. The advantage of a neural network is also its high resistance to noise data and the ability to use an unlimited number of independent variables.

At the same time, despite the success of the pilot projects and the demand for the solution in the market, replication of the service is difficult, since almost all large customers are not ready to use products on cloud technologies for security and data protection reasons.

\section{REFERENCES}

1. AkhmetzyanovK.R.,TurA.I.,KokoulinA.N.,YuzhakovA.A. (2020). Optimizatsiya vychisleniy neyronnoy seti [Optimization of neural network computation]. Vestnik PNIPU. Elektrotekhnika, informatsionnye tekhnologii, sistemy upravleniya [PNRPU Bulletin. Electrotechnics, Informational Technologies, Control Systems], 36.

2. Wiener N. (1968). Kibernetika, ili Upravlenie i svyaz'v zhivotnom i mashine [Cybernetics: Or control and communication in the animal and the machine]. Trans. from Eng. Moscow, Sovetskoe radio. 
3. Zuev V.N., Kemaykin V.K. (2019). Modifitsirovannyy algoritm obucheniya neyronnykh setey [An improved neural network training algorithm]. Programmnye produkty $i$ sistemy [Software \& Systems], 32(2), 258-262. DOI: $10.15827 / 0236-235 X .126 .258-262$.

4. KovalevD.A.(2020). Glubokieneyronnyeseti.Primenenie v meditsine [Deepneural networks. Medicalapplications]. Simvol nauki [Symbol of Science], 4, 29-31.

5. Kornina A. (2018). Mashinnoe obuchenie i neyronnye seti v biznese [Machine learning and neural networks in business]. Khronoekonomika [HronoEconomics], 2(10), 110-115.

6. Kurnikov D.S., Petrov S.A. (2017). Ispol'zovanie neyronnykh setey $\mathrm{v}$ ekonomike [The use of neural networks in the economy]. Juvenis Scientia, 6, 10-12.

7. Linder N.V., Arsenova E.V. (2016). Instrumenty stimulirovaniya innovatsionnoy aktivnosti kholdingov $\mathrm{v}$ promyshlennosti [Instruments of stimulation of innovative activity of holdings in the industry]. Nauchnye trudy Vol'nogo ekonomicheskogo obshchestva Rossii [Scientific Works of VEO of Russia], 198(2), 266-274.

8. Minsky M., Papert S. (1971). Perseptrony [Perceptrons]. Trans. from Eng. Moscow, Mir.

9. Morkhat P.M. (2018). Iskusstvennyy intellekt: nekotorye itogi obrabotki rezul'tatov provedeniya ekspertnykh oprosov spetsialistov [Artificial intelligence: Some results of processing the results of expert surveys of specialists]. Nravstvennye imperativy $v$ prave [Moral Imperatives in Law], 2.

10. Naumova M.Ya., Sharafutdinov A.G. (2015). Iskusstvennyyintellekt-budushcheesegodnya[ArtificialIntelligencethe future today]. NovaInfo.Ru, 34(2), 67-69.

11. Trachuk A.V., Linder N.V., Tarasov I.V., Nalbandyan G.G., Khovalova T.V., Kondratyuk T.V., Popov N.A. (2018). Transformatsiya promyshlennosti v usloviyakh chetvertoy promyshlennoy revolyutsii [Transformation of industry in the context of the Fourth Industrial Revolution]. Moscow, Financial University under the Government of the Russian Federation.

12. Tsvenger I.G., Nizamov I.R. (2017). Primenenie neyrosetevykh regulyatorov $\mathrm{v}$ sistemakh upravleniya elektroprivodami [Applying neural network regulators in system control of electric drives]. Vestnik Kazanskogo tekhnologicheskogo universiteta [Bulletin of the Kazan Technological University], 20(8), 111-114.
13. Yunusova L.R., Magsumova A.R. (2019). Algoritmy obucheniya iskusstvennykh neyronnykh setey [Algorithms for training artificial neural networks]. Problemy nauki [Science Problems], 7(43), 21-25.

14. Aleksander I., Morton H. (1990). An introduction to neural computing. London, Chapman \& Hall.

15. Ashby W.R. (1952). Design for a brain. New York, Wiley.

16. Bashkirov O.A., Bravermann E.M., Muchnik I.B. (1964). Potential function algorithms for pattern recognition learning machines. Automation and Remote Control, 25, 629-631.

17. Beitz C.R. (2018). The idea of human rights. New York, Oxford University Press.

18. Bowman D.M., Garden H., Stroud C., Winickoff D.E. (2018). The neurotechnology and society interface: Responsible innovation in an international context. Journal of Responsible Innovation, 5(1), 1-12.

19. Broomhead D.S., Lowe D. (1988). Multivariable functional interpolation and adaptivenetworks. Complex Systems, 2, 321-355.

20. Cowan J.D. (1967). A mathematical theory of central nervous activity. Ph.D. Thesis. London, University of London.

21. Hebb D.O. (1949). The organization of behavior: A neuropsychological theory. New York, Wiley.

22. Kohonen T. (1982). Self-organized formation of topologically correct feature maps. Biological Cybernetics, 43, 59-69.

23. McCulloch W.S., Pitts W. (1943). A logical calculus of the ideas immanent in nervous activity. Bulletin of Mathematical Biophysics, 5, 115-133.

24. Minsky M.L. (1954). Theory of neural-analog reinforcement systems and its application to the brain-model problem. Ph.D. Thesis. Princeton, NJ., Princeton University.

25. Minsky M.L. (1961). Steps toward artificial intelligence. Proceedings of the Institute of Radio Engineers, 49, 8-30.

26. Ramon y Cajal S. (1911). Histologie du systeme nerveux de l'homme et des vertebres. Paris, Maloine.

27. Rochester N., Holland J.H., Haibt L.H., Duda W.L. (1956). Tests on a cell assembly theory of the action of the brain, using a large digital computer. IRE Transactions on Information Theory, IT-2, 80-93. 
28. Rosellini W., D'Haese P.-F. (2017). Data is driving the future of neurotechnology with cranialcloud. $O N$ drugDelivery, 81, 44-47.

29. Rosenblatt F. (1958). The Perceptron: A probabilistic model for information storage and organization in the brain. Psychological Review, 65, 386-408.

30. Rumelhart D., Hinton G., Williams R. (1986). Learning representations by back-propagating errors. Nature (London), 323, 533-536.

31. Uttley A.M. (1956). A theory of the mechanism of learning based on conditional probabilities. Proc. of the 1st International Conference on Cybernetics, Namur, Gauthier-Villars, Paris, 83-92.

32. Uttley A.M. (1979). Information transmission in the nervous system. London, Academic Press.

33. Widrow B. (1962). Generalisation and information storage in networks of adaline "neurons". In: Yovitz M.C., Jacobi G.T., Goldstein G.D. (eds.). Self-Organizing Systems. Washington, DC, Sparta.

34. Willshaw D.J., Malsburg C. von der (1976). How patterned neural connections can be set up by self-organization. Proceedings of the Royal Society of London, Series B, 194, 431-445.

35. Winograd S., Cowan J.D. (1963). Reliable computation in the presence of noise. Cambridge, MA, MIT Press.

\section{ABOUT THE AUTHOR}

\section{Alexandr L. Lisovsky}

Candidate of economic sciences, general director of "NPO "Krypten" JSC.

Research interests: formation of the development strategy of industrial companies, change management, transformation of industrial production.

E-mail: al@aspp.ru 